\title{
Medical student disaster medicine education: the development of an educational resource
}

\author{
Ernst G. Pfenninger • Bernd D. Domres • \\ Wolfgang Stahl • Andreas Bauer • \\ Christine M. Houser • Sabine Himmelseher
}

Received: 8 July 2009 /Accepted: 4 November 2009 / Published online: 16 February 2010

(C) Springer-Verlag London Ltd 2010

\begin{abstract}
Background Disaster medicine education is an enormous challenge, but indispensable for disaster preparedness.

Aims We aimed to develop and implement a disaster medicine curriculum for medical student education that can serve as a peer-reviewed, structured educational guide and resource. Additionally, the process of designing, approving and implementing such a curriculum is presented.
\end{abstract}

Ernst G. Pfenninger and Sabine Himmelseher contributed equally to this paper.

Presented in part at the European Society of Anaesthesiology Annual Congress, Munich, Germany, June 2007, and the 14th World Congress of Anaesthesiologists, Cape Town, South Africa, March, 2008.

The views expressed in this paper are those of the author(s) and not those of the editors, editorial board or publisher.

E. G. Pfenninger $(\bowtie) \cdot$ W. Stahl $\cdot$ A. Bauer

Department of Anesthesiology, University Hospital of Ulm,

Steinhövelstr. 9,

89075 Ulm, Germany

e-mail: ernst.pfenninger@uni-ulm.de

B. D. Domres

German Institute for Disaster Medicine,

72076 Tuebingen, Germany

C. M. Houser

Department of Emergency Medicine, Academic Medical Center,

University of Amsterdam,

Amsterdam, The Netherlands

S. Himmelseher

Department of Anesthesiology, Klinikum rechts der Isar,

Technische Universitaet Muenchen,

81675 Munich, Germany
Methods The six-step approach to curriculum development for medical education was used as a formal process instrument. Recognized experts from professional and governmental bodies involved in disaster health care provided input using disaster-related physician training programs, scientific evidence if available, proposals for education by international disaster medicine organizations and their expertise as the basis for content development.

Results The final course consisted of 14 modules composed of 2-h units. The concepts of disaster medicine, including response, medical assistance, law, command, coordination, communication, and mass casualty management, are introduced. Hospital preparedness plans and experiences from worldwide disaster assistance are reviewed. Life-saving emergency and limited individual treatment under disaster conditions are discussed. Specifics of initial management of explosive, war-related, radiological/nuclear, chemical, and biological incidents emphasizing infectious diseases and terrorist attacks are presented. An evacuation exercise is completed, and a mass casualty triage is simulated in collaboration with local disaster response agencies. Decontamination procedures are demonstrated at a nuclear power plant or the local fire department, and personal decontamination practices are exercised. Mannequin resuscitation is practiced while personal protective equipment is utilized. An interactive review of professional ethics, stress disorders, psychosocial interventions, and quality improvement efforts complete the training.

Conclusions The curriculum offers medical disaster education in a reasonable time frame, interdisciplinary format, and multi-experiential course. It can serve as a template for basic medical student disaster education. Because of its comprehensive but flexible structure, it should also be 
helpful for other health-care professional student disaster education programs.

Keywords Disasters · Medical education · Curriculum · Medical students

\section{Introduction}

Disaster medicine education is indispensable for catastrophe preparedness. Although disasters have always been a part of world events, recent large-scale natural and manmade disasters have increased the focus on disaster medicine. As a consequence, medical schools in many parts of the world have begun to incorporate disaster-related topics into their curricula. In 2003, the Association of American Medical Colleges (AAMC) in the United States recommended that bioterrorism education be included in all medical school programs [1]. In Germany, federal laws have been enacted requiring that medical students be familiar with disaster medicine principles [2].

Analysis of the peer-reviewed literature indicates that few curricula for medical student disaster medicine education have been published. The AAMC report on bioterrorism training is more of an outline of educational objectives and activities than a specific curriculum. Its target group is US medical students in their last year of training, and builds on their growing knowledge and skills [1]. Covering a few aspects of medical disaster management, Parrish and colleagues [3] provide a description of a medical school course for 2nd year US students by briefly listing major subject headings. First taught by military experts, this course includes simulation exercises, such as a refugee scenario, and an infectious disease outbreak tracking exercise. In this format, however, operation execution appears to be the priority with less focus on medical care delivery. Markenson et al. [4] suggest core competencies and subject areas for terrorism, disaster, and public health emergency preparedness for health-care students based on professional school outlines. Referencing a proficiencies list, curricular matrices are proposed, but no steps or samples for implementation are presented. In a course for senior dental students, Glotzer and et al. [5] describe core competencies and dentists' roles within disaster response efforts focusing on bioterrorism; participation in a 4-h disaster life support course of the American Medical Association is also recommended to provide guidance regarding incidents with weapons of mass destruction.

Because a fully developed and comprehensive medical school disaster medicine curriculum was not available, the German government commissioned the development of a core medical student disaster medicine curriculum that could serve as a standardized template.

\section{Methods and curriculum development}

The dynamic process of curriculum development occurred in several stages

\section{Initial curriculum development and pilot testing}

Pilot versions of the curriculum were initially developed and utilized with faculty and student feedback over a 2-year period. The final curriculum resulted from these pilots, which were formally developed according to the six-step approach to curriculum development [6]. This included general and targeted needs assessment, definition of goals and objectives, choice of educational methods, and pilot implementation and evaluation. The pilots' contents were mainly based on government-funded research projects in which all curricula from German medical schools and postgraduate public health physician courses were evaluated for inclusion of disaster medicine-related themes [7]. It was noted that there was little and unstructured education in this area. The physicians of all $(n=477)$ German county disaster management agencies and district health authorities were also surveyed for additional input into needed disaster medicine competencies. With a nearly $100 \%$ response rate from the physicians surveyed, more than $92 \%$ expressed the necessity for better education. This resulted in the development of educational concepts for improving disaster preparedness at the under- and postgraduate level [7, 8]. Key components compiled here, disaster medicine topics of contemporary relevance, and expertise gained from student emergency medicine training were then combined to generate an independent lecture series. This was finally adapted into a disaster medicine curriculum for a 4th-year German medical school program. Medical education in Germany is formatted over 6 years. Students are thus expected to have had 3 years of clinical training in medical school when participating in the course. The implementation experience with the pilots was straightforward: The university dean and the department chair fully supported the idea of providing an introduction to the practices of disaster medicine at the student level. Course realization could thus readily be achieved: A core curricular team of physicians was assembled and scheduled all tasks. Internal and external professionals with expertise in subject areas were identified and invited to become teaching faculty. After coordination with medical school program planners, facilities for the in-house curriculum units (rooms, equipment) were organized with the lecture support staff. For the external units, collaborations with rescue and disaster response agencies were established to permit common exercises. For exchange and drill of non-physician professionals and students, agencies provided equipment, faculty, and their trainees to serve as mock victims for a mass 
casualty simulation. We presented physicians as preceptors and students in the role of future physicians. Finally, feedback on the curriculum from all participants was utilized to make alterations and improvements as needed.

\section{Revision of pilot curriculum and proposal for the government}

When the government requested a medical student disaster education plan, we offered a clear vision for goals and objectives of a comprehensive curriculum of core issues of disaster medicine based on our experience from the pilot courses: The first aim was not only to increase medical students' familiarity with the ideas and practices of disaster medicine, but to enhance their understanding of what occurs in a disaster, and where the limits and challenges faced by those delivering medical care under austere conditions lie. Second, improving knowledge of public health-relevant information on radiological/nuclear, biological, chemical, explosive, and other disaster-related health risks appeared to be important. Third, the opportunity to refresh and extend familiarity with basic and advanced life support, and to provide some limited experience with triage decision making was an additional benefit. Finally and as a long-term goal, we wished to enhance student interest in pursuing further disaster medicine expertise.

It was determined that scientific evidence-wherever available - should be incorporated and combined with professional expertise to build the content basis of the new curriculum $[9,10]$. Following analysis of international guidelines on disaster response training [11], peer-reviewed publications $[3-5,12,13]$, and programs such as the US Department of Homeland Security, Federal Emergency Management Agency (FEMA), and American Medical Association, learning objectives were fixed. After crossreferencing objectives with quality assurance criteria for medical education [14-16], topics were structured into a framework represented by subject headings. To identify the content details, a systematic literature search in Medline, Embase, and the Cochrane Library with the key terms "student, education, training, curriculum, course, competency, disaster, catastrophe, mass casualty, medicine, medical, preparedness, plans, and outcome" was conducted. Due to the relatively small number of relevant publications, complementary Internet searches were performed, and resources from websites such as from the FEMA program were included. Curricular committee consensus on those entities regarded to be most important was required for item inclusion. A blueprint for the core contents was then constructed in the form of modules with the goals as a matrix.

Because learning and memory benefit from multifaceted, stimulating environments $[17,18]$, we also decided to diversify the instructive strategies. This led us to include interactive discussions, teaching of problem-solving strategies, reviews of real-life experience, role playing, and exposure to exercises in "real-world" environments. Activities were assigned to suitable content modules, with a minimum of one-third of the curricular time being reserved for hands-on training. These units were designed to be performed with other professionals, such as fire fighters.

To evaluate the effectiveness of the curriculum, the results of a knowledge-based, pre-program written examination were compared with post-program examination results. Because the course was created to be part of the obligatory 4th-year German medical school program, the testing at course completion also served to fulfil requirements of the German educational system. Course evaluations for faculty and students were drafted to be used for further curricular developments $[6,14]$.

\section{Adoption of final curriculum}

As a way to approach administrative authorities (also outside of Germany), Fig. 1 shows the input and adoption of the final curricular version after review by interdisciplinary professionals and governmental bodies involved in disaster health care. Our final curricular proposal was accepted by the Leading Board of the German Civil Protection Committee. Small modifications were then made according to the wishes of the president and members of the German Society of Disaster Medicine and the Civil Protection Committee. The revision was then sent to governmental authorities, whose feedback produced another iteration in the process. The outcome was fine-tuned into formal alignment with global standards for quality improvement in medical education [14]. These included alignment with medical school mission statements, instructional methods of preparing students for life-long, selfdirected learning, or the provision of learning environments that resemble real-world scenarios. Following final Civil Protection Committee and governmental approval, a directive was provided to all directors of universities with medical schools instructing them to implement the curriculum (February 2007).

\section{Results, course content and implementation}

The creation of the final curriculum resulted in a course of 14 modules with each unit requiring approximately $2 \mathrm{~h}$ time:

Modules 1-3 (Table 1a) introduce the essentials of disaster medicine terminology, disaster assistance and law, management, and multidisciplinary coordination and communication systems. As key competencies, the tasks of assistance agencies, functional response roles, scopes of 
Fig. 1 Final curriculum development indicating stages of refinements and input from various professional and governmental bodies

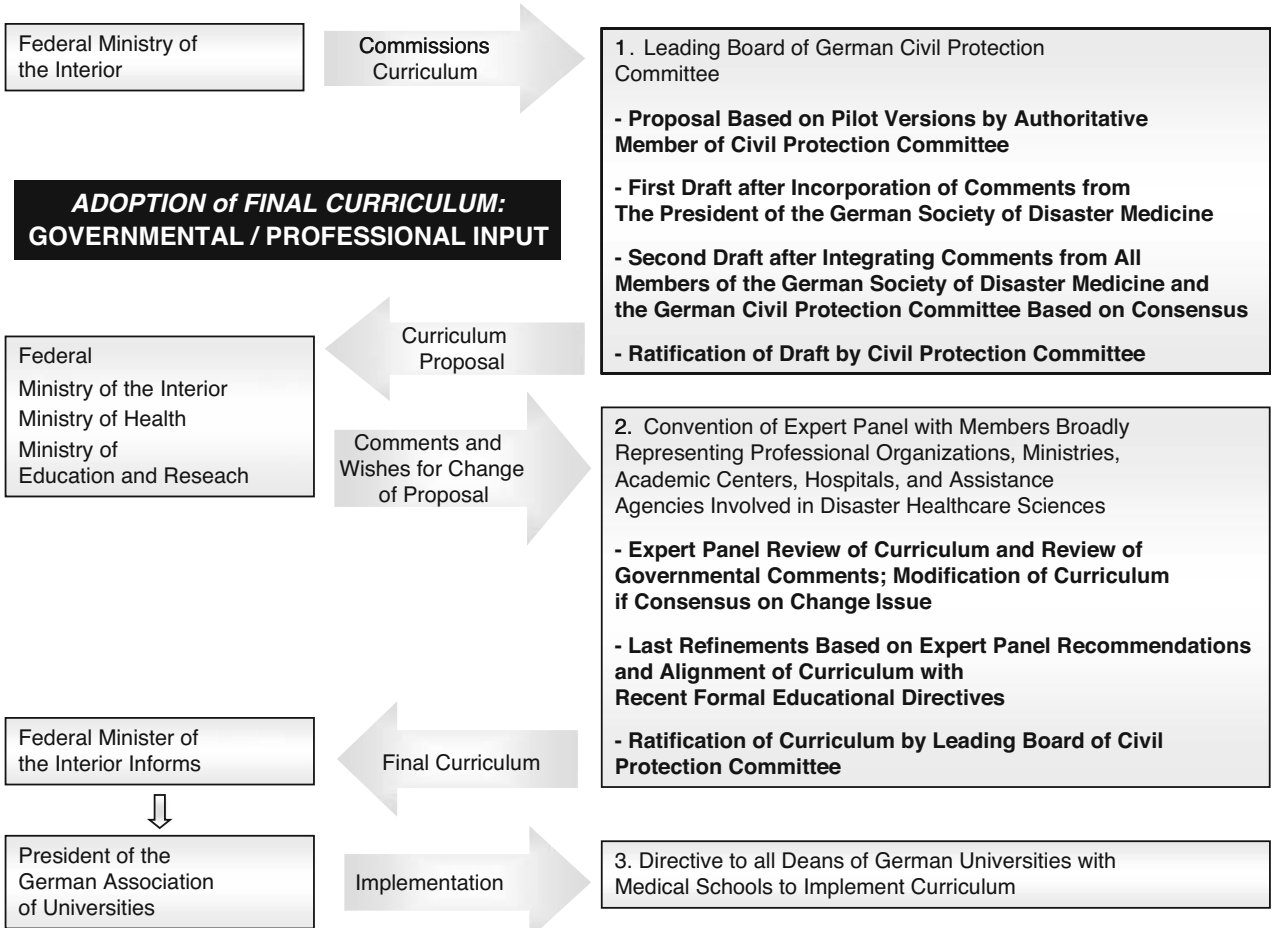

responsibility, lines of authority, logistical needs for mass casualties, and triage methods are taught. Students are familiarized with operational issues of disaster response strategies including problem-based learning discussions (PBLD).

Modules 4 and 5 (Table 1b) discuss hospital alarm and preparedness plans, with a focus on in-house and external incidents requiring high surge capacity. As core competencies, notification and mobilization orders are taught, and concepts of an institutional emergency plan are incorporated. Interactive review of past major community-threatening events and experiences from worldwide disaster and relief operations are utilized to built recognition of disaster health-care and medical assistance feasibility issues. Students learn the risks and limitations of relief operations, while focusing on the challenge of implementing care in the field.

Modules 6 and 7 (Table 1b) address knowledge and skills for triage and evacuation through participation in exercises. Students conduct triage and assume functional roles in real or virtual experiential training units.

To provide a hands-on experience and to increase student understanding of what occurs in a mass casualty management situation, we simulate a triage exercise in a small-group format (four students/two emergency physicians) as shown in Fig. 2. In brief, our interdisciplinary executed scenario is conducted at connected hallways and the hospital grounds in the setting of poor illumination, smoke, and loud noises. Well-trained, life-like moulage volunteers simulate casualties presenting with various disorders, from superficial injuries to moribund conditions, medical illnesses, and emotional trauma. To maximize the accuracy of the scenario, simulation patients have $20 \%$ severe, $20 \%$ moderate, and $40 \%$ light injuries, as is most typically seen in real-world events. In the multi-task exposure, students are first subjected to an instructive exercise, regarding role assignment, scenario description, protection and triage directives, and radio communication orders. They are not provided with any patient information prior to interaction with the mock victims, but are made aware of a constrained timeframe for the tasks. To be "authentic", students must put on full protective gear, helmets, and gloves. They carry radio communication devices for frequent contact with the operational command. The hands-on exercise is then run in a step-by-step manner, starting with patient search: After they are located, patients must be checked for vital functions and examined. Following differential diagnosis, they must be triaged, and treatment goals and management priorities must be defined. Disposition decisions must be documented on paper records and communicated to the command center. The compressed timeframe exercise ends with a radio announcement. As a debriefing exercise, students receive performance assessment with respect to future roles as physician, collaborator, and communicator in a contextual feed-back.

Modules 8 and 9 (Table $1 \mathrm{~b}$ and c) teach life-saving and specific emergency medical care for various disaster situations, containing first aid and specific approaches to 
Table 1 Modules 1-14

Modules, learning activity

Educational goal

Core contents

a Medical Student Disaster Medicine Curriculum, Modules 1-3

Module 1, Lecture and PBLD

Introduction to disaster medicine, terminology

Disaster assistance

Typology

Laws and regulations

Module 2, Lecture and PBLD

Disaster medical management

Functional operations

Incident command systems

Coordination structures

Functional roles

Information management

Module 3, Lecture and PBLD

Specific disaster medicine

Tactic disaster medical management

To develop skills in principles of tactically managing mass casualties and large numbers of patients suffering, e.g., from combined conventional trauma and thermal injuries

To realize the architecture and organization management necessary for coping with mass casualty incidents and large-scale acutely ill patients in a coordinated way regulations for civil protection and disaster preparedness to develop an understanding for
general disaster management

To consider the heterogeneity of disasters

b Medical Student Disaster Medicine Curriculum, Modules 4-8

Module 4, PBLD and Interactive Review

Hospital preparedness and disaster management planning To follow orders and principles of hospital
alarm and evacuation plans

Module 5, PBLD and Interactive Review

Presentation of past disasters and review of assistance experiences
To evaluate and understand feasibility issues of providing medical support and health care in the field and under disaster conditions based on experience from worldwide disaster assistance operations
Glossary and common disaster medicine definitions, differences between disaster and emergency medicine, different phases of disaster management

Principles of disaster assistance

Disaster assistance organization, assistance agencies and structure

Natural and technological disasters, terrorism, man-made disasters, civilian disorders, environmental and other threats

Regulative and administrative issues for civil disaster protection, warfare disaster protection laws, rescue service and hospital laws, governmental resources, and authorities

Mass casualty disposition, treatment area, transport issues

Tasks of rapid-intervention-units (sanitary/psychosocial care)

Disaster contingency plans command and control structures, functional operations center

Coordination, integration, and cooperation of multi-agency rescue and assistance response

Functional response roles, e.g., lead emergency physician, organizational leader, and technical command post

Communication, coordination

Patient assessment and triage: triage levels, tags, registration; primary emergency care, multitasking and operational management phases (e.g., patient collection, treatment area, transport)

Logistical requirements for care of burn-injuries, mine blast, and missile-hit victims (including high-speed bullet injuries), mass trauma management

Hospital disaster laws

Hospital alarm plans

Hospital preparedness plans for

- Management of external disasters with mass casualties suffering from multiple injuries, intoxication, infections, and/or radioactive contamination

- Management of in-house disasters with fire incidents and hospital evacuation

Presentation of past disasters and disaster assistance experience gained in the field, e.g., from lead emergency physicians, operations in earthquake assistance, explosions, highly contagious infectious diseases, repatriation 
Table 1 (continued)

Modules, learning activity

Educational goal

Module 6, Experiential Training

Preclinical and clinical triage exercise

To perform triage decisions in reality simulation

Module 7, Experiential Training

Evacuation exercise

To apply operational principles and steps of action for evacuation procedures

\section{Module 8, Lecture and PBLD}

Life-saving disaster emergency medical care

To learn concepts of life-saving emergency disaster medical care

c Medical Student Disaster Medicine Curriculum, Modules 9-11

Module 9, Lecture and PBLD

Specific disaster emergency medical care To get to know principles of specific for various situations including bioterrorism incidents

\section{Module 10, Lecture and PBLD}

Radiological and nuclear threats, accidents with radioactive material, radiation illness and syndrome, decontamination
To learn principles and basic medical care for management of incidents with radiologic/nuclear agents and contaminated victims

\section{Experiential training}

Decontamination after radiation exposure

\section{Module 11, Lecture and PBLD}

Chemical and toxicological threats from hazardous materials and goods, transport risks, acute poisoning and toxic syndromes

Poisoning epidemiology, risk assessment for mass intoxications

\section{Experiential training}

Decontamination after chemical poisoning

flights, and with the German Federal Armed

Forces Medical Corps in world crisis regions

Triage training exercise: real or virtual scenario simulation rescue exercise, e.g., explosion with mass casualties and blast, mechanical, and thermal injuries of all triage levels

Command post exercise, real or virtual: e.g., evacuation organization and evacuation of a hospital, school, part of town, etc.

Under disaster conditions: provision of life-saving emergency medical care to adults and children, e.g., shock therapy, pain treatment, and sedation

Disaster emergency medical first aid, specific measures

Surgical and medical treatments of burn and thermal injuries and illnesses from explosive, warfare and biological agents

Epidemiology and approaches to terrorist attacks, weapons, and highly contagious infectious diseases, sentinel cases

Specific dangers of radiological/nuclear agents, associated illnesses and radiation syndrome

Self protection, protection and detection equipment, special intervention units

First aid medical treatment, isolation and radioactive decontamination, decontamination operations in case of mass trauma combined with contamination injuries

To be exposed to practical aspects and procedures of decontamination

To get to know principles of medical countermeasures for management of incidents with dangerous chemical substances, hazardous materials and goods

To experience exposure to decontamination procedures

Decontamination exercise or decontamination demonstration, e.g., in nuclear power plant or with the fire brigades

Identification and risk assessment of hazardous materials, chemicals and goods, and associated toxic syndromes

Management of acute intoxications and poisonings, threats from specific poisons

Self protection, precautions

First aid medical treatment, e.g., enhanced elimination of toxins, use of antidotes, adjunctive services, e.g., poison emergency centers and toxicology laboratories

Triage in case of mass casualties with toxic syndromes Decontamination measures and exercise 
Table 1 (continued)

$\begin{array}{lll}\text { Modules, learning activity } & \text { Educational goal contents }\end{array}$

d Medical Student Disaster Medicine Curriculum, Modules 12-14

Module 12, Lecture, PBLD, and

Interactive Review

Ethics and professionalism

Quality assurance

Module 13, PBLD and Interactive Review

Psychosocial care

Module 14, Course Completion

Closing examination

Evaluation of educational success

Learner and educator assessment of course
To develop familiarity with ethical codes and the duty of care relevant to disaster conditions

To understand quality improvement efforts and risk management programs for disaster medical response

To comprehend concepts of psychic stress response

To learn techniques to deal with psychic reactions caused by exposure to disaster scenarios

To recognize need for help and to initiate psychosocial support

To demonstrate gain of knowledge and skills

To assess educational value of course

To maintain continuous curriculum development and improvement in course quality
Geneva Convention and amended protocols, ethical codes of conduct, humanitarian imperatives, social, moral, and ethical challenges of disasters

Quality control performance indicators, incident monitoring, tools for risk and critical event assessment, structured improvement approaches

Appropriate documentation

Case presentations for identification of critical incident stress reactions and review of therapeutic interventions

Treatment approaches to acute and delayed critical incident stress reactions, acute and chronic stress syndromes, post-traumatic stress disorders

Structure and tasks of psychosocial emergency intervention units

Operational strategies of psychosocial treatment

Student final examination, oral and/or written test

Comparison of pre-program versus post-program student test results

Student and faculty summative and formative course evaluation injuries, burns, explosions, blasts, and illnesses from warfare and biological agents. Emphasising terrorist attacks and highly contagious infectious diseases, core competencies for care of explosive, warfare, and biological incidents are included. Minimally acceptable treatment and limitations for patienttailored therapy in case of mass casualties are discussed.

Modules 10 and 11 (Table 1c) teach the dangers and management of radiological/nuclear and chemical hazardous materials. Treatment approaches to radiation and/or chemical injuries are discussed as core competencies. Options for protection, first aid, decontamination, enhanced elimination, and antidotes are reviewed. Students learn how victims with combined trauma and toxic injury are triaged. At a nuclear power plant or fire department, the design and state of preparedness of such facilities are evaluated, and equipment is demonstrated.

To provide a practical experience of a decontamination procedure and to get students personally involved in how it feels to work in protective gear, we offer a combined unit of didactic, interactive, and hands-on training at the fire department (Fig. 3). After incident presentation, a lecture on radiological/nuclear and chemical hazardous substances is given. Technical equipment, mobile units, protective gear, and contamination detection devices are demonstrated. Use of protective gear is explained and a decontamination suite described. As hands-on exercises, students put on full protective gear and gas masks. Being both protected and hampered by this gear, they must attempt to manage the airway, intubate, and ventilate mannequins. This hands-on program serves as a real-world simulation experience, reproduced by (1) heat load under the multilayer overgarment, (2) enhanced personal respiratory efforts, (3) restricted visual fields because of the gas mask, and (4) interference with manual dexterity by the chemical protective gloves. Finally, they are subjected to a personal decontamination process. After debriefing, the module ends with an interactive review and analysis of past incidents.

Modules 12 and 13 (Table 1d) deal with challenges of ethical, professional, psychosocial, and quality control criteria of medical disaster management themes. As key competencies, professional behavior and obligations under disaster conditions are discussed. Students learn critical aspects of 
Fig. 2 Algorithm of student immersion in mass casualty rescue simulation exercise
SIMULATION EXERCISE: MASS CASUALTY MANAGEMENT

\begin{tabular}{|c|c|c|}
\hline \multicolumn{3}{|c|}{ DEBRIEFING } \\
\hline $\begin{array}{l}\text { EVALUATION } \\
\text { Strategic and } \\
\text { Triage Decisions }\end{array}$ & $\begin{array}{c}\frac{\text { ASSESSMENT }}{\text { Diagnostic and }} \\
\text { Medical Performance }\end{array}$ & $\begin{array}{c}\text { DISCUSSION } \\
\text { Management and } \\
\text { Communication Skills }\end{array}$ \\
\hline
\end{tabular}

STUDENTS

and PROFESSIONALS

\begin{tabular}{|c|c|c|c|}
\hline \multicolumn{3}{|c|}{ INSTRUCTIONS } & \\
\hline $\begin{array}{l}\text { ASSIGNMENT } \\
\text { Functional Response Roles } \\
\text { Team Assembly } \\
\text { Personal Protection }\end{array}$ & $\begin{array}{l}\text { STRATEGY } \\
\text { Triage Tags } \\
\text { Patient Identification } \\
\text { Documentation }\end{array}$ & $\begin{array}{l}\text { COORDINATION } \\
\text { Command System } \\
\text { Use of Mobile Radios } \\
\text { Communication Orders }\end{array}$ & $\begin{array}{c}\text { STUDENTS } \\
\text { and } \\
\text { PROFESSIONALS }\end{array}$ \\
\hline
\end{tabular}

STUDENTS

MOCK VICTIMS,

and

PROFESSIONALS

(3) Differential Diagnosis, Injuries and Syndrome Assessment

2. In 90-secTimeframe: Rapid Vital Function Check and Physical Examination

(1) Victim Search and Localisation

acute and delayed stress disorders (anxiety and grief), and the psychosocial resources, such as crisis intervention units, available to provide specialised assistance. To understand quality improvement efforts, students gain familiarity with assessment tools and incident monitoring to evaluate functional components of disaster response systems.
Module 14 (Table 1d) is designed to assess the educational success of the course. Students demonstrate the acquired knowledge and attitudes in an oral and/or written examination [6]. According to the German regulations, each medical school has the freedom to design the format of the examinations chosen for their student evaluations.
Fig. 3 Flowchart of the module with the fire fighters or at a nuclear power plant focussed on education of incident management with radioactive and hazardous chemical substances

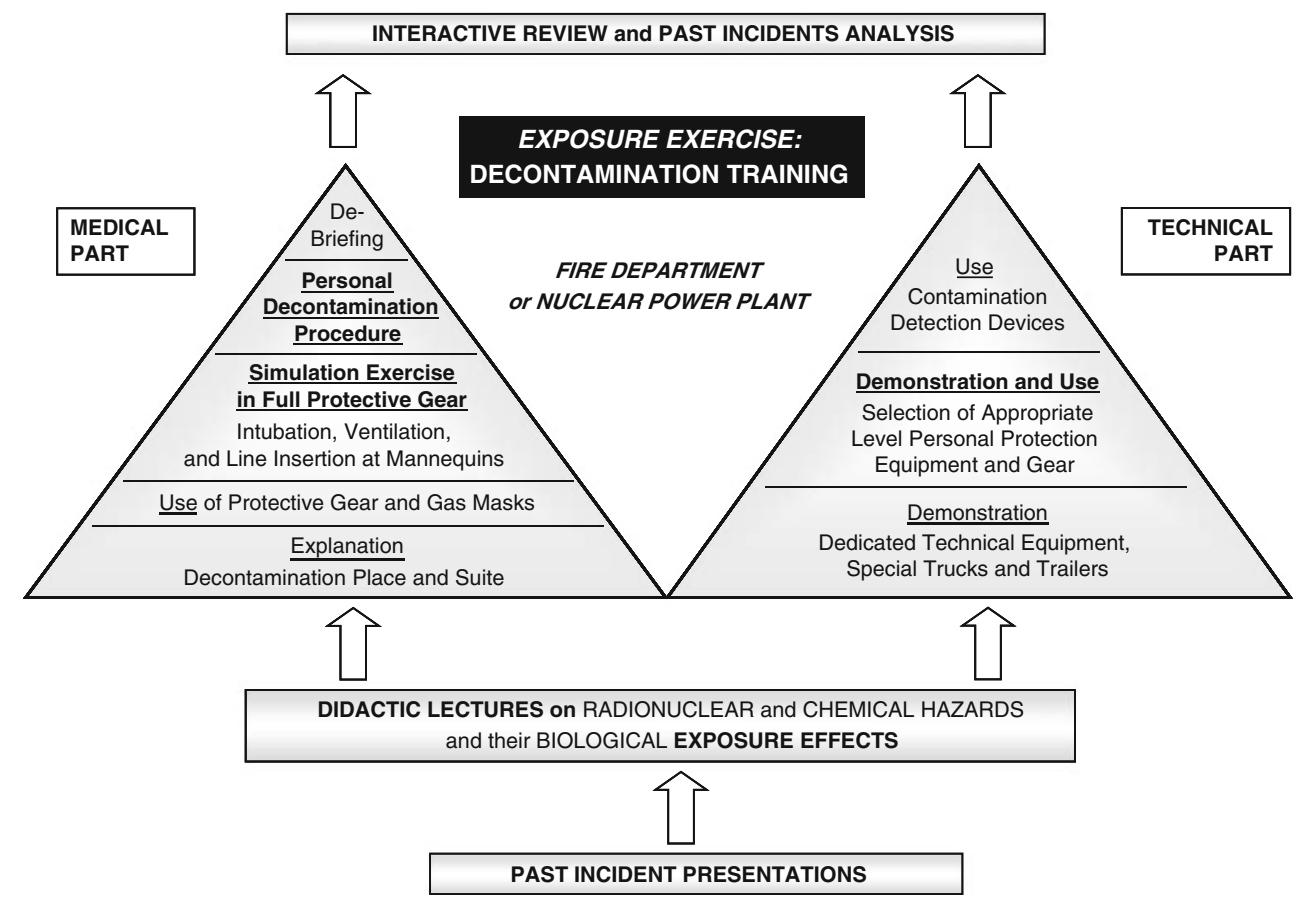




\section{Discussion}

To our knowledge, this curriculum is one of the first publications of a comprehensive medical student disaster medicine curriculum that covers major contemporary aspects of basic disaster medicine management. The developed course offers a cross-professional design in a readily adaptable structure, is focussed on actual scenarios, and has been aligned with quality criteria for improved teaching approaches $[14,16,19]$. At a time when medical schools in numerous countries are struggling to find a place for disaster medicine in their programs, this educational topic is worthy of research and discussion. Our work may be used as an educational resource, with the opportunity to adapt the basic template to various locations, threats, and systems. An introduction to care principles will be of value to preparedness in any locale, even though disaster response plans and conditions may differ among countries, or states and cities of a single country. The curriculum also provides resources for endeavors of organizations such as the Section in Disaster Medicine of the European Society for Emergency Medicine, which has as a current goal the development of a standard European disaster medicine curriculum for medical school undergraduates [20].

The curriculum is now implemented in nine German medical schools. The analysis of the implementation process and curricular success has been pre-defined for a period of 5 years, and was begun 3 years ago. However, all medical schools that have implemented the curriculum have so far reported that they now teach disaster medicine components with a scope and depth much broader than within emergency medicine, pointing out the additional value for disaster preparedness and disaster medical management. Seven of them report that they have implemented a fully independent course, and five of the medical schools base their teachings on an educational program that is in complete conformity with the curriculum developed.

Because derivation and details for medical student competency definitions differ widely $[3,4,6,11]$, we used a consensus-building approach for outlining competencies and thus the framework for the educational goals of this curriculum. Requests of the Education Committee Working Group of the World Association for Disaster and Emergency Medicine [10], disaster medicine-related competencies as indicated in emergency medicine or radiology curricula, courses recommended by professional organizations, the literature and expert opinion were addressed as far as available [7, 21-23]. Deriving subject matter from thus predefined goals provided the advantage of readily defining the main targets for core contents. The competency structured design also permits flexibility in addressing a multiplicity of disaster situations, including floods, hurricanes, earthquakes, and surveillance-related health prob- lems, as well as care for vulnerable populations such as children and hospitalised patients.

Educational goals were weighted in terms of time allocation to assist medical school planners operating with more limited discretionary curricular time. In our opinion and circumstances, a 14-module course composed of 2-h units provides adequate student education and mock disaster exposure in a reasonable period. Some themes important for disaster preparedness are also addressed in other medical school programs, such as in medical microbiology, toxicology, and environmental medicine [7]. The topics we targeted for this curriculum, however, do not overlap with other student programs. Emergency medicine curricula for medical students, when present in medical school curricula at all, do not typically focus on disaster medicine or disaster response. Introduction to emergency medicine focuses on maximum possible, individual patient-tailored care $[9,21,23]$ and-if included - principles of management of mass casualties at a discrete scene. This is intended to address disaster medicine conditions in which extraordinary treatment demands exceed resources, and where incidents of great magnitude requiring external assistance for management may reach epidemiological dimensions [10].

When planning the experiential units, we attempted to ensure that costs were minimized: For cost containment, selection of a teaching cadre with background in emergency or disaster medicine who collaborates with local disaster response agencies is most effective. Additional teachers can join in, and after receiving instructor training, faculty development may be supported through ongoing participation in areas of disaster medicine interest. Exercise scenarios may not be available in all medical school environments, but can, in most cases, be established through a "joint training/learning venture" with existing response agencies. Because agencies are obliged to carry out simulation exercises and drill their own staff, curriculum units can be performed with mutual benefit. Exercise costs can thus be kept low, and mainly derive from transport to external locations. For an estimation of costs, Table 2 provides activity-based descriptions for organizing and implementing the curriculum.

There are several limitations to this work. There is no evidence that introducing medical students to disaster medicine directly affects patient outcomes. Nevertheless, educational efforts for important medical topic areas have to be started at some point in medical school, and this can be evaluated over time. Of course, the provision of onetime disaster medicine training will only allow for a passing familiarity with terms and concepts. To retain competencies, it will be necessary to refresh and assess knowledge and skills periodically, and we are planning to implement educational refresher courses in our German national program. Moreover at present, we cannot comment on 
Table 2 Task assignment for estimation of organizational burden and curricular implementation costs

\begin{tabular}{|c|c|}
\hline Curricular activity & Mission description \\
\hline Program management & $\begin{array}{l}\text { Development of a local organizational structure responsible for curricular activities: } \\
\text { team recruitment, appointment of managers and departmental staff in-charge, task assignment } \\
\text { Identification of internal and external experts and invitation as teaching cadre } \\
\text { Establishment of collaboration with local disaster response agencies and planning of common } \\
\text { external units, exercises, and simulations } \\
\text { Teaching and preceptor assignment for internal and external units } \\
\text { Institution of curriculum within medical school program and coordination of units with program planners } \\
\text { Organization of facilities and equipment for in-house units with university's lecture support staff } \\
\text { Organization of transport to external units } \\
\text { Management of administrative and reporting issues } \\
\text { If necessary: establishment of financial recording, billing, and reimbursement system }\end{array}$ \\
\hline $\begin{array}{l}\text { Faculty development/continuous } \\
\text { professional growth }\end{array}$ & $\begin{array}{l}\text { Future faculty development through involvement in existing teaching activities, plans, and team meetings } \\
\text { Faculty instructor training } \\
\text { Optional: professional growth through participation in related internal and external developmental } \\
\text { programs for university educators and disaster medicine preparedness }\end{array}$ \\
\hline $\begin{array}{l}\text { Quality assurance/continuous } \\
\text { curricular development }\end{array}$ & $\begin{array}{l}\text { Development of data collection system } \\
\text { Analysis of ongoing evaluations from learners and educators } \\
\text { Use of course assessments and experiences for orientation, end-of-course team meetings, } \\
\text { and future progress }\end{array}$ \\
\hline Student support & $\begin{array}{l}\text { Provision of curricular schedule and learning objectives } \\
\text { Provision of lecture compilation (syllabus or CD) as course content workbook and base } \\
\text { for self-directed learning } \\
\text { Development of data collection system and analysis of student examination data } \\
\text { Development of reporting system for examination grades }\end{array}$ \\
\hline $\begin{array}{l}\text { Maintenance of } \\
\text { partnerships/collaborations }\end{array}$ & Continuous encouragement and support for internal and external partnerships and collaborations \\
\hline $\begin{array}{l}\text { Running of administrative/overhead } \\
\text { expenditures }\end{array}$ & If necessary: management of direct and indirect expenditures, such as telecommunication costs \\
\hline Other pursuits & $\begin{array}{l}\text { Designing of plans for course revisions or curricular enhancements, such as integration } \\
\text { of e-learning methods }\end{array}$ \\
\hline
\end{tabular}

how well the curriculum performed, and what the overall success of the course will turn out to be. This evaluation has been designed for a time period of 5 years.

Moreover, exposing students to mock disaster scenarios and simulation exercises is far from real-world conditions. Certainly, students will not intubate patients in full protective gear in real disasters and will of course not be included in first rescue response teams in compromised environments. Nevertheless, based on our experience as university educators, they benefit from the knowledge and skill-building hands-on exercises that may serve as a basic training for future medical practice in all kinds of emergency situations. Our students also receive clear instruction that they are not trained search and rescue personnel. For our course, we thus try to prevent the possibility that simulation-based medical education experiences could cause student over-confidence and misjudgement of competency [24].
In its first design, our curriculum consists of "traditional, face-to-face, instructor-student interactions and hands-on experiences," and does not use electronic (e-) learning methods. E-technology holds the promise for distance education of disaster response concepts and virtual reality simulations. Because blended curricular formats integrating e-methods may enhance inter-professional exchange without compromising pedagogy [25], they may be included in future curricular versions.

\section{Conclusion}

A curriculum is provided for medical student disaster medicine education at an advanced level of medical school training, along with information regarding the process involved in creating such a program at a national level. We wish to emphasize that the curriculum has been 
designed for medical students in a particular system and that there are various concepts for basic disaster medicine education. Due to its comprehensive, interdisciplinary nature, instructive design, and flexible structure, however, the curriculum can benefit other health-care professional systems by serving as a model curriculum, and facilitating refinement and testing of other existing, but perhaps as yet unpublished models.

Acknowledgments The work reported in this publication reflects the input from many students, faculty, and representatives of various professional, societal, and governmental bodies. We wish to acknowledge in particular the contribution of the following members of the German Civil Protection Committee: I. Beerlage, MD, Professor, Division of Social and Healthcare, University of Applied Science, Magdeburg-Stendal; L. Clausen, MD, Professor, Disaster Research Division, Department of Sociology, University of Kiel; A. Flieger, MD, Federal Office of Civil Protection and Disaster Assistance, Bonn; W. Marzi, MD, Federal Office of Civil Protection and Disaster Assistance, Bonn; P. Sefrin, MD, Professor, Division of Preclinical Emergency Medicine, University of Wuerzburg; J.W. Weidringer, MD, The State Chamber of Physicians of Bavaria, Munich; W. Weis, MD, Professor, Federal Office for Radiation Protection, Neuherberg, Germany.

This curriculum has been recommended by the Board of Directors of the German Society of Disaster Medicine, the Leading Board of the Civil Protection Committee at the Ministry of Interior of the Federal Republic of Germany, and the German Federal Office of Civil Protection and Disaster Assistance. It has been ratified by the standing conference of the Ministers of Education and Cultural Affairs of the countries of the Federal Republic of Germany and has been recommended by the Minister of the Interior of the Federal Republic of Germany for national implementation.

Conflicts of interest Apart from departmental funding, no outside support in the curriculum development or manuscript preparation has been received. The authors declare that they have no conflict of interest or disclosure in any way related to this work.

\section{References}

1. Association of American Medical Colleges (2003) Training future physicians about weapons of mass destruction: Report of the expert panel on bioterrorism education for medical students. Washington DC, AAMC. Available via. http://www.aamc.org/ newsroom/bioterrorismrec.pdf. Accessed 28 June 2009

2. Government of the Federal Republic of Germany (2002) Code of Federal Regulation 8. Nouvelle of German Medical Licensure Act. Federal Law Gazette I; Part 1; Paragraph 2, 405 et sequentes. Berlin, Germany

3. Parrish AR, Oliver S, Jenkins D, Ruscio B, Green JB, Colenda C (2005) A short medical school course on responding to bioterrorism and other disasters. Acad Med 80:820-823

4. Markenson D, DiMaggio C, Redlener I (2005) Preparing health professions students for terrorism, disaster, and public health emergencies: core competencies. Acad Med 80:517-526

5. Glotzer DL, More FG, Phelan J et al (2006) Introducing a senior course on catastrophe preparedness into the dental school curriculum. J Dent Educ 70:225-230
6. Kern DE, Thomas PA, Howard DM, Bass EB (eds) (1998) Curriculum development for medical education: a six-step approach. The John Hopkins University Press, Baltimore

7. Pfenninger E, Himmelseher S, König S (2004) Investigation of the integration of the german public health service into the medical care for catastrophe preparedness and response in the Federal Republic of Germany [extended English abstract]. Federal Office of Civil Protection and Disaster Assistance, Federal Republic of Germany. Zivilschutzforschung Neue Folge Band 54. media consult, Bonn, Germany. Available via. http://www.bbk.bund.de/cln 027/ nn_398730/SharedDocs/Publikationen/Publikationen20Forschung/ Band_2054,templateId=raw,property=publicationFile.pdf $/$ Band $\%$ 2054.pdf. Accessed 4 July 2009

8. The UK General Medical Council (2003) Tomorrow's doctors. Recommendations on undergraduate medical education. Available via. http://www.gmc-uk.org/education/ undergraduate. Accessed 30 June 2009

9. Gaddis GM, Greenwald P, Huckson S (2007) Toward improved implementation of evidence-based clinical algorithms: clinical practice guidelines, clinical decision rules, and clinical pathways. Acad Emerg Med 14:1015-1022

10. de Boer J, Dubouloz M (eds) (2000) Handbook of disaster medicine. Emergency medicine in mass casualty situations. International Society of Disaster Medicine, 2nd edn. Brill Academic Publishers, Leiden

11. Seynaeve G, Archer F, Fisher J et al (2004) International standards and guidelines on education and training for the multidisciplinary health response to major events that threaten the health status of a community. Prehosp Disaster Med 19(suppl 2):S17-S30

12. Lund A, Lam K, Parks P (2002) Disaster medicine online: evaluation of an online, modular, interactive, asynchronous curriculum. CJEM - JCMU 4:408-413

13. Hsu EB, Thomas TL, Bass EB, Whyne D, Kelen GB, Green GB (2006) Healthcare worker competencies for disaster training. BMC Med Educ 6:1-9

14. World Federation for Medical Education / International Task Force (2007) WFME global standards for quality improvement in medical education. European specifications. WFME Office Copenhagen, Denmark. Available via. http://www.wfme.org. Accessed 15 June, 2009

15. Swing SR (2007) The ACGME outcome project: retrospective and prospective. Med Teach 29:648-654

16. ENQU Report to Ministers Meeting in Bergen (2005) Standards and guidelines for quality assurance in the European higher education area. Available via. http://www.enqu.eu. Accessed 5 June 2009

17. Patel VL, Yoskowitz NA, Arocha JF (2009) Towards effective evaluation and reform in medical education: a cognitive and learning sciences perspective. Adv Health Sci Educ Theory Pract. Jan 24 [Epub ahead of print]

18. Harden RM (2006) Trends and the future of postgraduate medical education. Emerg Med J 23:798-802

19. Boonyasai R, Windish DW, Chakraborti C, Feldman LS, Rubin HR, Bass EB (2007) Effectiveness of teaching quality improvement to clinicians. A systematic review. JAMA 298: $1023-1037$

20. Della Corte $\mathrm{F}$ for the Section in Disaster Medicine of the European Society for Emergency Medicine (2008) Minutes of the $1^{\text {rst }}$ EuSEM Section in Disaster Medicine Meeting. Munich, Germany, September 15, 2008. Available via. http://www.eusem. org/Pages/Sections/DisasterMedicine/EuSEM_Disaster_Medicine. html Accessed 4 July 2009

21. Shayne P, Gallahue F, Rinnert S, Anderson CL, Hern G, Katz E (2006) Reliability of a core competency checklist: assessment in the emergency department: a standardized direct observation assessment tool. Acad Emerg Med 13:727-732 
22. Alexander AJ, Bandlera GW, Mazurik L (2005) A multiphase disaster training exercise for emergency medicine residents: opportunity knocks. Acad Emerg Med 12:404-411

23. 2005 EM Model Review Task Force, Thomas HA, Binder LS, Chapman DM et al (2006) The 2003 model of the clinical practice of emergency medicine: the 2005 update. Emerg Med 48:e1-e17

24. Wenk M, Waurick R, Schotes D, Wenk M, Gerdes C, van Aken HK, Pöpping DM (2009) Simulation-based medical education is no better than problem-based discussions and induces misjudgement in self-assessment. Adv Health Sci Educ Theory Pract $14: 159-171$
25. Carbonaro M, King S, Taylor E, Satzinger F, Snart F, Drummond J (2008) Integration of e-learning technologies in an inter-professional health science course. Med Teach 30:2533

Ernst G. Pfenninger is Professor at the Department of Anesthesiology, University Hospital of Ulm, Ulm, Germany. He is a lead emergency physician who has been involved in disaster medicine research, preparedness and education for more than 20 years. 